\title{
Pleasure and time in senior dance: bringing temporality into focus in the field of ageing
}

\author{
Clary Krekula* (D) \\ Department of Social and Psychological Studies, Karlstad University, Karlstad, Sweden \\ ${ }^{\star}$ Corresponding author. Email: clary.krekula@kau.se
}

(Accepted 30 June 2020; first published online 12 August 2020)

\begin{abstract}
Population ageing and discourses on healthy ageing have led to a growing interest in social dancing for seniors. While senior dance has been described as both common and contributing to good health, the fundamental connection between bodily and temporal dimensions has been fairly neglected. As a result, there is a risk of portraying dance among older adults as a general practice, while at the same time the senior dance's potential to shed light on relations between temporality and ageing is not utilised. Based on qualitative interviews with 25 women and eight men, aged 52-81, in Sweden, whose main leisure activity was dancing, this article sheds light on this knowledge gap by illustrating the pleasurable experiences of senior dance. The results illustrate that the pleasurable experiences of dancing can be understood as three different experiences of temporality: embodied experience of extended present, an interaction with synchronised transcending subjectivities and age identities with unbroken temporality. The results also highlight the central role that temporal aspects play in processes around subjectivities in later life, as well as the close connection between ageing embodiment and temporality. They also illustrate the ability of dance to create wellbeing, not only through its physical elements, but also through the sociality that constitutes the core of dancing. In light of these results, the article argues that the temporal processes relate to individuals' diverse relationship with the world and that they therefore play a central role in subjective experiences of ageing.
\end{abstract}

Keywords: affective observation; critical age studies; dance in later life; embodiment and ageing; embodied relatedness; embodied temporality; extended now; time and temporality

\section{Introduction}

Population ageing and discourses on healthy ageing have led to a growing interest in activities among older adults (Brown et al., 2008; Krekula et al., 2017). Dance among seniors is one example of an activity that has attracted increased attention, which can be understood in the light of the changing social and cultural meanings of ageing (Ronström, 1998) and the general focus on healthism and increased health awareness (Crawford, 1980; Petersen and Lupton, 1996; Greenhalgh and

\footnotetext{
(C) The Author(s), 2020. Published by Cambridge University Press. This is an Open Access article, distributed under the terms of the Creative Commons Attribution licence (http://creativecommons.org/licenses/by/4.0/), which permits unrestricted re-use, distribution, and reproduction in any medium, provided the original work is properly cited.
} 
Wessely, 2004), including among older people (Gilleard and Higgs, 2014; Krekula et al., 2017; Marshall, 2018).

Dance is a bodily and temporal practice (Wallenstein, 2008), which is manifested in dance being based on time aspects such as rhythm, tempo, sequences, synchronisation and duration ( $c f$. Zerubavel, 1981; Marion, 2008). Despite this, these aspects and their mutual interaction have been rather overlooked in dance among older adults. The limited problematisation of these fundamental dimensions contributes to dancing being presented as a fairly general practice, while at the same time dancing's potential to shed light on relations between temporality and ageing has not been utilised.

Time is not only central in dance; it is also an ever-present dimension of human life (Durkheim, [1912] 2008; Zerubavel, 1981; Adam, 1990). It constitutes a central aspect of subjectivities and the creation of meaning around, and staging of, social positions (Flaherty, 1987; Krekula and Johansson, 2017). Since experiences and markers of time constitute a starting point for constructions of age categories and age relationships, the temporal dimensions have a special position in constructions of age that cannot be found among other social locations. In their introduction to critical age studies, Krekula and Johansson (2017) argue that the focus on time in chronological age, along with individuals continuously identifying themselves with new age identities during their lifecourse, makes the age number an easily accessible explanation to use in interpretations of experienced changes. This use of age references can be seen against the background that we lack an adequate tool to convey lived experience of time despite the central place of temporal process in daily life (Zerubavel, 1987). As a result, experiences of time run the risk of being confused with, and sometimes misinterpreted as, age-related processes. All in all, this points to time aspects having a central place in everyday experiences of age and to the importance of shedding light on correlations between temporality and ageing (Krekula et al., 2017; Katz, 2018; Krekula, 2019).

In this article, I provide a contribution to this research field. Based on qualitative interviews with people aged 50 and above in Sweden whose main leisure activity is to engage in dancing, I illustrate that the pleasurable experiences of senior dance can be understood as three different experiences of temporality: embodied experience of extended present, an interaction with synchronised transcending subjectivities and age identities with unbroken temporality. In light of this, finally I argue that the temporal processes relate to individuals' diverse relationship with the world and that they therefore play a central role in subjective experiences of ageing.

\section{Literature review}

Overall, senior dance is described as both common and contributing to good health and wellbeing (Connor, 2000; Keogh et al., 2009). Generally, research on dance in later life has primarily addressed the phenomenon as a health-enhancing practice and thus mainly portrayed it as a physical activity (Ronström, 1998; Krekula et al., 2017). In particular, a number of qualitative and intervention-centred studies with a medical perspective show that dancing can have beneficial effects on the health and mental wellbeing of seniors (for a survey, see e.g. Connor, 2000; Keogh et al., 2009). This approach is in line with a widespread scientific and societal 
discussion on the importance of activities for what is described as healthy and successful ageing (see e.g. Rowe and Kahn, 1998).

Along with research on the health-enhancing aspects of dance, a more limited number of studies have described the social meanings of dance and illustrated that dancing among older adults contributes to community and intimacy, and offers a context in which their own bodies become an aesthetic object (Cooper and Thomas, 2002; Nadasen, 2008; Paulson, 2009), gives feelings of self-actualisation (Thomas, 1995; Paulson, 2009; Roberson and Pelclova, 2014), provides an outlet for creativity (Moe, 2014), and contributes to both positive and negative emotional energy (Paulson, 2009; Alfredsson Olsson and Hekinen, 2019). Moreover, studies on the organising of dance from a critical age perspective have illustrated that the organising is based on norms of active ageing and that the organisers regard dance as part of a silver economy (Krekula et al., 2017), i.e. as part of a growing range of goods and services offered to senior citizens (Klimczuk, 2016). Previous research on dance among older adults can thus be described as two fairly well-separated research fields that emphasise it as either a physical or a social practice.

However, it is not just older adults' dance practice that is described as a health-enhancing activity; similar comments are made in relation to mixed-age groups doing belly dancing (Kraus, 2017) and ballroom dancing (Marion, 2008), not to mention dance therapy in which the connection between physical movement and emotions is central (Grönlund et al., 2005). Rather, the difference in descriptions of dance for various age groups lies in the one-sided delineation of older adults' dancing as a mainly physical activity because of the focus on physical health. Such dichotomy between physical and social aspects in relation to dance for younger and mixed-age groups has been challenged by claims that dancing rather constitutes embodied practices in which physical and social dimensions are intertwined. This can be seen, for example, in research which has shown that dance unites body, soul and mind (Stewart, 2000), that belly dancing is an activity infused with spiritual meaning (Kraus, 2017), that bodily movements as postures and gestures can create spiritual experiences (McGuire, 2007) and that dance can create experiences such as a 'tango high' in the form of feeling at ease (Savigliano, 1998: 104). Even though this research approach has gained little ground in research on senior dance thus far, it is in line with research on embodiment within critical gerontology, which has recurrently illustrated that experiences of ageing are physically mediated and shaped in their lived material contexts (see e.g. Tulle, 2008; Hurd Clarke and Korotchenko, 2011; Katz, 2018).

One exception to the limited research on the temporal aspects of senior dance, as mentioned above, can be seen in a study of the organisation of senior dances, where Krekula et al. (2017) illustrate that the temporal organisation of allocating more- or less-attractive time slots for different age groups creates an age normality based on younger ages that marginalises the older age groups. Their results demonstrate that this implicit time organisation constitutes a way of 'doing age', i.e. sustaining age relations through a subtle form of power. Their focus, however, is on the social and organisational level and does not shed light on individuals' subjective experiences of temporality in dance.

However, the lack of emphasis on the temporal aspects of dance among older adults does not mean that this is an unresearched area. Once again, we can note 
a difference in the dominant research approach depending on the practitioners' age. Research on dance among younger and/or mixed-age groups has shown that people can become so intensely involved in the dance that they forget about everything else around them, losing track of time and their surroundings. These processes have been shown in dances as different as belly dance (Kraus, 2009, 2017), American country dance (Flinn, 1995), Pilipino folk dance (Gilmore, 2000) and in the Kono dance from East Sierra Leone (Hardin, 1988). The elaborate embodied temporal elements of dance also show in statements that temporal aspects, such as timing, togetherness and floorcraft, are key for adjudicators' assessment in dance competitions (Radler, 1998). Furthermore, it has been stated that dancing is a temporal activity which serves as a medium of expression and is composed of movement through space that unfolds in time (Thrift, 1997; Vatakis et al., 2014). The above-described differences between different research fields on dance, depending on the age groups in focus, contribute to the representation of dance practice as two separate and distinct activities, where older people's dance experience is at risk of being trivialised due to a narrower approach.

\section{Theoretical starting points: passion and temporality}

The experiences discussed in this article, commitment to and pleasure of participating activities (such as dancing), have been discussed using concepts such as passion and flow. Passion is a concept that generally reflects a strong sense of enthusiasm for something (Fourier, [1851] 1968; Lawrie, 1980) and which is recurrently characterised by an intensity that can 'take us with command of a situation' (Lawrie, 1980: 111). Like passion, the concept of flow refers to activities which are pleasurable and immediately self-rewarding. Flow, however, focuses on individuals' phenomenological descriptions of indulging in an activity and is related to intrinsically motivated activities, with clear challenges and goals and immediate feedback on goal attainment (Csikszentmihalyi, 1990; Lavigne et al., 2012). Even though these types of elements can be found to a certain extent in parts of the material analysed in this article, this definition is more specific than needed here to create an overall framework for the experiences discussed. In this study, the concept of passion is therefore used to refer to descriptions of pleasurable feelings in dancing. However, passion has a variety of definitions. A central aspect of my understanding of the concept is not only the strong emotional element, but also that passion for something entails devoting time to it (Vallerand and Verner-Filion, 2013).

This article focuses on how dance relates to experiences of time. These analyses are based on the concept of temporality, which provides a framework for the processes which connect the past, the present and the future, as well as a framework for individuals' perceptions of the correlations between these dimensions (West-Pavlov, 2012; Leccardi, 2014; Krekula, 2019).

These analyses are also based on theoretical works on choreography, where the concepts of 'living presence' and 'the time of presence' have been used to clarify individuals' experiences of an extended present in focused activities, where the past and the future appear absent (Dobbels, 2008: 127). The concepts emphasise that experience of time that moves from the past to the future is always dependent 
on an outward-facing perspective, i.e. dependent on you focusing on external aspects rather than directing attention and reflection inward towards your own person. These concepts align with arguments that experiences of a broadened now, i.e. the experiences of a time-extended quality, can be understood as numerous 'nows' that are piled on top of one another and thus create a 'specious' extended present (Varela, 1999; Laroche et al., 2014). The above stresses that characteristics of actions (such as dancing) are key to how individuals perceive time and, especially, how they perceive the present (Zerubavel, 1981; Adam, 1990).

The analyses below also concern questions of how interactions in dance can be understood from a time perspective. Central to these arguments are statements that being together in time emerges from the relational dynamics of embodied interactions and their flexible co-regulation (Laroche et al., 2014). This directs focus to social interactions simultaneously shaping time and being shaped by time (Zerubavel, 1981; Adam, 1990), which also emphasises that bodies mediate and create temporal synchronisation between individuals (Zerubavel, 1981). An example of this is how the varying rhythms of dance affect how the interaction between the participants is shaped. Zerubavel (1981: 65) emphasises the temporal aspects of interactions by claiming that temporal symmetry, where individuals' activities are synchronised, is 'one of the fundamental principles of social organisation'.

The concept of temporality is also described as an aspect of subjectivity (e.g. Flaherty, 1987). Relevant to the analyses of the article is that social positions like gender (Butler, 1990), whiteness (Ahmed, 2007) and age (Krekula and Johansson, 2017; Krekula, 2019) are understood as temporal practices in which previous enactments are both eternalised and transformed through iteration. This serves as a starting point for the discussion below on how the pleasure of dance relates to experienced age identities.

\section{Context, material and method}

In Sweden, which is the national context of this study, dance became increasingly associated with mass movements such as the labour movement and the sobriety movement emerging at the end of the 19th century and the first half of the 20th century, although dance events remained mainly organised for young age groups (Ulvros, 2004). Dance events for older people are currently a widespread phenomenon, and reportedly one person in four aged 60-79 and one person in five aged 50-59 goes dancing (Starrin and Steffner-Starrin, 2013).

The present study is part of a major research project on dance in later life in the context of three case studies (Yin, 2009), in which the research team collaborated on the data collection and then individually proceeded to analyse and interpret the material based on their own thematic focus and research questions. The methodological approach of the study is ethnographic and explorative (Hammersley and Atkinson, 1995), with material mainly collected through qualitative interviews (Brinkmann and Kvale, 2015) and participatory observations (Burgess, [1982] 1991) in three analytically demarcated dance contexts: non-profit association dance, social dance and fitness dance. The first category is arranged by senior associations as well as folk dance societies. Social dance refers to public and mixed-age events that aim to provide pleasure, social contacts and dating opportunities. 
Fitness dance has a pronounced focus on health, sometimes arranged at a gym. Even if the categorisation of dance contexts is not clear-cut, it has contributed to a greater variation in the material. The defining of 'older adults' was done empirically. In some cases, the dance events only welcomed visitors aged 50+, while in other cases categorisation was based on the respondents' own identification with the 'senior' or the 'gold' attribute, which usually turned out to be $65+$.

The interviews were preceded by participatory observations. In addition to observations of the dance contexts with their interactions, informal rules and routines, attention was paid to the researchers' own physical, emotional and sensory experiences, which guided the continuous creation of working hypotheses and research questions. Because of the explicit use of one's own affections, I refer to these as affective observations. This approach contributed to a deeper understanding of the multiple meanings of dance. For example, by partaking in choreographically organised show dancing in groups, we experienced the difficulties as well as the satisfaction of different movements. This helped us to ask relevant follow-up questions in the interviews.

The present article is based on the analysis of qualitative interviews with 25 women and eight men in Sweden, aged 52-81, who go dancing on a regular basis. The respondents were mainly recruited during the affective observations and, in some isolated cases, through so-called snowball sampling in which researchers asked respondents to suggest persons to contact (Creswell, 1998). The ambition was to achieve great variation in terms of age, gender, dance context and experiences of dance through life. The uneven distribution of the number of women and men reflects reality as women outnumber men in dance contexts. This does not affect the analyses of this article, which does not focus on gender aspects, but instead looks at experiences of the pleasure of dance and the interaction between temporality and ageing that appears therein.

The interviews, conducted by the author and project colleagues, lasted around 60-90 minutes and were carried out at a place chosen by the respondents, such as in their homes or in a coffee shop. Interviews were recorded digitally and transcribed verbatim. The interview guide focused on broad themes, such as experience of dancing in a life perspective, the significance of dancing in later life, intimacy and body issues in dancing, as well as experience of norms and violations of norms in connection with dancing. For this article, I focused on the parts of the interviews where the respondents spoke of the joy and pleasure of dancing. The selection of quotes is also based on definitions of passion, where I focused particularly on the sections of the material where the informants talk about the time they spend dancing.

The multi-step analysis aimed to clarify the processes in question from the respondents' perspectives (Blaikie, 2007). The first step involved a thematic analysis of the transcribed material (Guest et al., 2012) to capture their reasoning regarding the meanings of dance and the aspects they related to pleasure and joy. I therefore began by identifying and analysing descriptions of the pleasures of dancing. These analyses shed light on experiences of time as a common aspect within three areas; focus on one's own body, interactions and age identities. As a second step of my analysis, I searched for more statements about time, such as experiences of time while dancing and time spent doing the activity. By doing so, I wanted to ensure 
that the analyses included all relevant material. This meant that the temporal dimensions emerged through the analysis rather than as a result of specific questions asked. Since the broad themes of the interview guide did not specifically include time and time horizons, and no questions about the future were asked, the material collected predominantly came to centre on accounts and experiences relating to the past and the present only.

\section{Passion for dance as experience of time}

The empirical material comprises an abundance of depictions of dancing as a pleasurable, sensual experience. This emerges, for instance, in descriptions of dancing as a 'slow feeling', 'going completely mad on the dance floor from the euphoria I feel' as well as statements that dance is an experience comparable only 'to sex'. Conversely, respondents reported being miserable and feeling '20 years older in a day' when they could not go dancing because of illness, for instance.

The material also reveals that the respondents spent a great deal of time on dancing, as shown in the following type of statement:

I dance jitterbug on Monday evenings, there are jitterbug games on Tuesday evenings, and daytime dance on Wednesdays; on Thursdays there are polska dances and on Saturdays there might be a dance event in some amusement park.

Many of the interviewees also centred their lives around dance, saying 'our adult children are well aware that we can't babysit on Wednesdays and Sundays'. The descriptions of intense emotions in sensual experience coupled with the amount of time spent on the dance floor are in line with definitions of passion (Lawrie, 1980; Vallerand and Verner-Filion, 2013), and with the argument that priority of activities can be measured in terms of time ascribed (Zerubavel, 1981). The descriptions of the pleasure of dancing can therefore be understood as expressions of passion for dance. Below, I illustrate that this passion relates to three different experiences of temporality that concern experiences of one's own body, the interaction with the surroundings and experienced age identities.

\section{Embodied experience of extended present}

When respondents talked about what they liked about dancing, descriptions such as the following were frequent: 'The music is terrific and there is rhythm, you get caught up in it, that's what makes it fun'; 'I like dancing with him, a jitterbug that's not too fast' and 'The tempo is of course important, which means that I like a certain type of music and song and set of instruments better than other types'. In this way, the respondents explicitly referred to temporal patterns such as rhythm and tempo. In other words, the sensual experience of time is highlighted as a central aspect of the passion for dance.

When this physical experience of time is clarified in the material, it relates to a specific form of subjectively perceived time, an extended now. An example of this comes from a 55-year-old woman who says 'What you feel in the dance is as if the world is disappearing. You are in a cloud of happiness.' The statement that 'the world is disappearing' could be understood as an expression of how that which 
is perceived to be left in space is a tangible sense of being here and now, and the past and the future do not exist when the situation and the emotions were defined. The interpretation that this involved an exclusive focus on the present is supported by the respondent's attempts to explain further: 'It is a state of extreme wellbeing. And relaxation and the sense that nothing else exists at this moment.'

Another example of how experiences of an extended now contribute to the pleasure of dancing was provided by a 74-year-old woman describing belly dancing:

And then when we laid down for a break, the tears came. It is euphoric. Something in the body feels good. Then of course you don't think of anything else. You are relaxing, you see.

A 72-year-old woman described similarly how the external world was shut out when dancing with a man mastering the steps of a dance:

I can relax, I can close my eyes and feel that someone is holding me. And I dare to close my eyes and just follow him. It's fantastic. I don't need to be in control when I trust someone else to take care of that.

The quote shows that the informant, who is led in the dance by her male dance partner, does not feel the need to have control over what is happening around her, but can fully devote herself to the dance and focus on the harmonious movement of two bodies and the feelings this evokes. Against the background of dance norms, where men are expected to lead in partner dances, it is possible that this points to the idea that there might be gendered variations in these experiences of an extended now in dance. It is not, however, possible to explore this further in my material.

The results above that shed light on experiences of what I refer to as an extended now relate to previous research illustrating the existence of what is known as living presence in dance (Varela, 1999; Dobbels, 2008; Laroche et al., 2014), and to research on dance among younger and/or mixed-age groups illustrating that dancers can be absorbed in the dance to the extent that they lose their sense of time (see e.g. Savigliano, 1998; Kraus, 2009, 2017). They also highlight the central role that the perception of one's own body, rather than of one's surroundings, has in these processes and that this time experience is described in terms of both wellbeing and euphoria. The statements above about the ageing body as a source of passion and pleasure, effectively challenge one-sided accounts of physical ageing as unilaterally problematic, something which has been especially prominent in terms of women's ageing (for a discussion, see e.g. Hurd Clarke and Korotchenko, 2011; Krekula, 2016).

\section{An interaction with synchronised transcending subjectivities}

The second experience of temporality in the material that relates to passion concerns the interaction with music as well as with dance partners. A 72-year-old man provides an example of how the pleasure of dancing can be related to the experience of being one with the music: 
There are different rhythms and I like the cha-cha, and if you are in rhythm with the music then I enjoy it a lot. It feels good.

A woman engaged in social dance similarly said, 'You live in the music somehow.' In the words of Zerubavel (1981), these statements can be interpreted as synchronisation with the music.

The positive experience of being synchronised with the music is also emphasised in a 67-year-old man's description of how certain types of music can ruin the pleasure of dancing:

Sure, there may be pieces played at standard dance events that do not feel good to dance to. And some big band music and arrangements, Glen Miller-type, for instance, may not work so well for common people because you feel out of sync.

The empirical material further shows that similar synchronisation also takes place in the interaction between dance partners, as illustrated by this quote from a 55 -year-old woman who practises social dance:

We are so in tune when dancing and that is so enjoyable in some way. To be a bit cheeky, I admit that I'm a bit turned on. The dance turns me on. Dancing in harmony. Every step feels right. We almost become one. It's not the bodily proximity but the feeling that everything works. I can't put it in words.

In the quote, the pleasure of dancing is described in terms of sensual feelings, although not primarily because of bodily proximity but rather the synchronisation of the two dancing bodies when 'everything works'. In other words, it is the synchronisation in the interaction between the dancers that is presented as the basis for the passion of dancing. The quote also illustrates that the synchronisation can contribute to the borders between the two dancers becoming more blurred, as if the two 'almost become one'.

The idea that synchronised interaction can be perceived as pleasurable can also be found in statements about group dancing, like in this quote below where a 73-year-old woman describes the pleasure of fitness dance:

The music is important and the joy of moving and following the beat. And then the fact that we all feel like a group, everyone is moving in that direction and it feels like, 'yes, now we all did the right thing'. It's stylish! This is also important.

The quote shows how successful interaction in the group creates joy and also a sense of fellowship, i.e. an experienced collective identity. Here, as in the quote above, it is the synchronised movements that are credited as creating the feeling of belonging between dance partners.

The results above highlight that an aspect of the pleasure of dancing relates to the interaction with its synchronisation with the music and dance partners. This seems to involve two aspects, namely the synchronisation of the dancing bodies and the feeling of forming a 'we' rather than an 'I' to which this synchronisation contributes. In other words, it is both the experience of interactive corporality 
and the experience of crossing the borders of subjectivity that contribute to the passion of dancing. These results are in line with previous research that argues that dance both contributes to a sense of community (Collins, 2004) and connects body, mind and soul (Stewart, 2000). They also illustrate the positive emotions and the pleasure that this may bring about. Overall, these results show that embodiment in later life crosses understandings in terms of simple dualisms. While previous research on the meanings of physical ageing has discussed the correlation between an 'inner subjectivity' and an 'externally limiting body' to a fairly large extent (see e.g. Featherstone and Hepworth, 1991; Biggs, 2004), the results above point to the complexity that may also exist in how individuals demarcate their surroundings. Instead of distinct borders between the body and the surroundings, the results highlight the existence of what could be referred to as an embodied relatedness, where the experience of one's own corporality ties in with the surroundings, both temporal aspects as well as rhythms and physical present relationships.

\section{Age identities with unbroken temporality}

While the forms of temporal experiences discussed above relate to individuals' embodiment, the third theme relates to the dancers' identification with age categories and the judgements of other people, which has been discussed in research using the term identities (see e.g. Stets and Burke, 2000; Stryker and Burke, 2000). This is demonstrated in statements about the pleasure of dancing being based on feeling and appearing younger, i.e. that the pleasure of dancing is related to younger age identities than the chronological age in question. An example of this can be found in the following quote from a 65-year-old woman describing how she feels when she practises belly dancing:

It gives more in the way that you get to experience an inner, let's call it, sensuality or something. You feel sort of younger, fresher, cooler and that feeling cancels out all existing taboos. Preconceived ideas that ladies of my age shouldn't be doing such things are not around there, no one sniffs at you.

In the quote, an age identity in the form of feeling younger than one's chronological age relates to experiences of sensuality and of being 'fresher' and 'cooler'. In the material, there are statements about younger age identities among both women and men. A 68-year-old man gives examples of how you may appear younger with the help of specific dance movements:

You might want to show your feelings for the lady, that you're vital and in good condition, that you dance well and are sort of younger than you look. You try to keep up a hard tempo when shaking and so on. And when you dance a regular dance, you try to express that you like music, can keep the beat decently, and that you enjoy the music and live in it.

In this example, it is the ability to maintain a high tempo in the dance and become one with the music that is described to convey a younger age. 
The younger age identities also manifest as an experience of remaining the same over time. An example of this is provided by a 64 -year-old woman when she describes the situations where she feels young in social dance:

Yes, I guess it's when you're asked to dance. Perhaps several times. Then maybe you feel that you still got it on the dance floor. But that's nice.

Descriptions of 'still' being sought after as a dance partner shed light on the temporal dimension of this age identity, where it is identified in relation to a repetition of previous experiences. It also implies an expectation that this may come to change in the future, that there may come a day when you are no longer seen as the person you once were, in this case that you are no longer wanted as a dance partner.

In the above quote about feeling sensual in the dance, the female informant also speaks of dancing enabling her to challenge taboos about how older women are expected to behave. Dance's ability to provide space for enabling new forms of staging of gendered age can also be found in the quote below:

It's about trusting one's body and ability, because mentally it's really about not being afraid of being looked at. And then if I do something I shouldn't at my age, if we dance really closely my husband and I ... when we dance a bit semidecadently and giggle together, then it happens. If I go dancing, I'm allowed to pretend to be 30 . Then you're a bit immature, more daring and a bit more unbridled perhaps. (55-year-old woman, social dance)

In the quote, the informant expresses that she does not view 'semi-decadent' and 'giggly' dance as expected at her age, and that she codes characteristics like being bold and immature to younger ages (for further details of age coding, see Krekula, 2009). Like the informant above, she emphasises that it is dancing as context and activity that enables these renegotiations of what is possible to do as an older adult. Expressions such as 'no one sniffs at you' and being 'allowed to pretend' to be younger than one's chronological age indicate that the people around them are seen as permissive. Other statements, such as 'People who come here have a completely different mindset', offer further support for the interpretation that it is the absence of judging looks that enables what is described as transcending taboos in the dance.

At a general level, the results above show that dancing also provides pleasure by creating conditions for feeling younger than the actual chronological age. These dimensions of the attraction of dance can be understood as an opportunity to present oneself in a way that is not expected of an older person and as a way to combat age norms. The results further illustrate that these age identities are shaped against notions of both the past and the future, and that it is identification with the past, i.e. perceiving oneself as the same as before to some extent, that creates a positive experience of dancing. In other words, it is the experience of an unbroken temporality that is at the centre of this theme about the pleasure of dancing. These results relate to previous studies that argue that temporal dimensions are central in the doing of age (Krekula and Johansson, 2017). They contribute to this by illustrating these types of temporal expressions and highlighting the positive emotions that they may include. These results are aligned with research showing that experiences of 
being younger than the chronological age, which has also been discussed using the concept subjective age, correspond with a higher degree of subjective wellbeing (see e.g. Kaufman and Elder, 2002; Westerhof and Barrett, 2005).

\section{Concluding discussion}

In this article, I discuss dance among older people with the aim of contributing to a deeper understanding of the pleasurable aspects of dance. The analyses show that pleasure is based on three experiences of temporality: experiences of an extended present, synchronisation with the surroundings and an experienced unbroken temporality. I further argued that these relate to the dancer's experience of their own body, their interactions and age identities. While previous research has observed that dance can create positive emotions (Paulson, 2009), this article adds further knowledge of the underlying processes by identifying the specific aspects that create the passion for dance among older adults. They also illustrate the ability of dance to create wellbeing, not only based on its physical elements, but also on the sociality that constitutes the core of dancing.

The concept of extended present was introduced above to clarify experiences of the past and the future not being at the foreground for the individual. The concept is related to time research that emphasises how the present is characterised by 'colonising' the future (see e.g. Leccardi, 2014). There is, however, an important difference between the two theoretical approaches. While the problematisation of how the present gains dominance over individual ability to predict and plan for the future is based on macro-sociological analysis of social change centring on social acceleration (Rosa, 2013), I use the concept of extended present to clarify individual phenomenological perception of the present and the future as not being situationally demarcated.

The results of this study further highlight different aspects of dancing. While statements about the pleasure of moving to music in close interaction with others describe dance as a particular form of activity where the interaction between embodiment and temporality is central, the informants' descriptions of how dance creates conditions to transcend taboos for older adults also direct attention to dance as a particular context with locally gendered (age) norms. This indicates that both of these aspects need to be emphasised in future studies on dance among older adults. In this study, both activity and context contribute to the description of dance as an arena that enables relationships between individuals, characterised by synchronisation and confirmation. This does not mean that other, also contradicting, relations with the surrounding world do not exist in dance contexts. They are not discussed here because the focus of the study is on the pleasure of dancing.

A theoretical premise of the study is that past, present and future are intimately connected in individual meaning-creation (see e.g. Leccardi, 2014). Nevertheless, the future perspective is not apparent in the results reported above. This should not be construed as evidence that older people do not act in relation to a future in these contexts. The limited and vague observations made regarding the future in the material only reflect that the interview guide did not include time and time horizons as a central them.

An important aspect of the presented results relates to their connection to previous research, studies focusing on older dancers as well as on dance among 
younger people or mixed-age contexts. Instead of describing dance in later life as an activity that fundamentally differs from dance among younger people, the results show similarities between different age groups in terms of the meanings of dancing and its complex embodiment. This serves as a reminder that the similarities and differences of different age groups should not be taken for granted, but rather studied empirically. This relates to statements that age is done relationally and contextually. While easily accessible concept pairs, such as 'experienced older peoplestrong younger people', contribute to the fact that some assumptions about age categories move between and establish themselves in a variety of contexts, constructions of age categories vary between different contexts (Krekula et al., 2018). Thus, the circulation of key concepts, such as age, is not a neutral transfer, but rather an active process where local actors and discourses negotiate the definitions (Ahmed, 2012).

In relation to the connection of embodiment and temporality in dance, this study also raises questions about the knowledge of embodiment in later life that transpires in analyses of the pleasure of dancing, and about what the temporal perspective adds to research on ageing. We can start by noting that the results above illustrate that the pleasure of dancing relates to several forms of individuals' relationship with the world. It relates to both relationships between mind and body and between body and the surroundings, and it includes corporality in both a physical and symbolic sense. The common denominator of these experiences of temporality is that they are based on the body as a mediator.

The mentioned areas have been discussed to varying degrees in gerontological research. The relationship between body and mind is a fairly well-debated area, where questions about older bodies' ability to express an inner subjective self have been central (see e.g. Featherstone and Hepworth, 1991; Biggs, 2004). On the other hand, the aspects that I have referred to as embodied relatedness those relating to the embodied relationship between the individual and the surrounding world - have attracted less attention. However, the results in this article show that also these aspects are central to individuals' everyday experiences of ageing, and that there is therefore reason to highlight them further.

Finally, the results above illustrate the connection between experiences of ageing embodiment and of temporality. They also clarify the central role that temporal aspects have in processes around subjectivities in later life. The empirical material and analyses above show that it is not possible to distinguish the two dimensions from each other in the processes of embodiment and temporality. In the context in question, the individuals' experience of body and time appears as a twofold experience which can be defined through concepts such as embodied temporality and/or temporal embodiment. This can be seen as an example of the central role that temporal processes have in subjective experiences of ageing, thus constituting an argument for future studies on the temporal meanings of ageing.

Acknowledgements. The author is indebted to the colleagues participating in collecting data for the project dealing with older people's dancing. Many thanks to Eva Adolfsson Olsson, Markus Arvidson, Andreas Henriksson and Satu Hekinen.

Financial support. This work was supported by the Swedish Foundation for Humanities and Social Sciences (2016-2019). 
Ethical standards. At Karlstad University ethical review is not required for studies that are not dealing with sensitive topics.

\section{References}

Adam B (1990) Time and Social Theory. Cambridge: Polity Press.

Ahmed S (2007) A phenomenology of whiteness. Feminist Theory 8, 149-168.

Ahmed S (2012) On Being Included. Racism and Diversity in Institutional Life. Durham, NC: Duke University Press.

Alfredsson Olsson E and Hekinen S (2019) 'I will never quit dancing'. The emotional experiences of social dancing among older persons. Journal of Aging Studies 51, 100786.

Biggs S (2004) Age, gender, narratives, and masquerades. Journal of Aging Studies 18, 45-58.

Blaikie N (2007) Approaches to Social Enquiry. Advancing Knowledge. Cambridge: Polity.

Brinkmann S and Kvale S (2015) InterViews: Learning the Craft of Qualitative Research Interviewing. Los Angeles, CA: Sage.

Brown CA, McGuire FA and Voelkl J (2008) The link between successful aging and serious leisure. International Journal of Aging and Human Development 66, 73-95.

Burgess RG (ed.) ([1982] 1991) Field Research: A Sourcebook and Field Manual. London: Routledge.

Butler J (1990) Gender Trouble. New York, NY: Routledge.

Collins R (2004) Interaction Ritual Chains. Princeton, NJ: Princeton University Press.

Connor M (2000) Recreational folk dance: a multicultural exercise component in healthy ageing. Australian Occupational Therapy Journal 47, 69-76.

Cooper L and Thomas H (2002) Growing old gracefully: social dance in the third age. Ageing \& Society 22, 689-708.

Crawford R (1980) Healthism and the medicalization of everyday life. International Journal of Health Services 10, 365-388.

Creswell JW (1998) Qualitative Inquiry and Research Design. London: Sage.

Csikszentmihalyi M (1990) Flow: The Psychology of Optimal Experience. New York, NY: Harper \& Row.

Dobbels D (2008) Tyngdens rum. Paul Virilio i samtal med Laurence Louppe och David Dobbels. In Caprioli C and Wallenstein S-O (eds), Koreografier (Skriftserien Kairos No. 13). Stockholm: Raster Förlag, pp. 117-141 .

Durkheim E ([1912] 2008) The Elementary Form of Religious Life. New York, NY: Dover Publications.

Featherstone M and Hepworth M (1991) Images of ageing. In Bond J and Coleman P (eds), Ageing in Society: An Introduction to Social Gerontology. London: Sage, pp. 250-276.

Flaherty MG (1987) Multiple realities and the experience of duration. Sociological Quarterly 28, 313-326.

Flinn J (1995) American country dancing: a religious experience. Journal of Popular Culture 29, 61-69.

Fourier C ([1851] 1968) The Passions of the Human Soul and Their Influence on Society and Civilization, 2 vols. New York, NY: Kelley.

Gilleard C and Higgs P (2014) Ageing, Corporeality and Embodiment. London: Anthem Press.

Gilmore S (2000) Doing culture work: negotiating tradition and authenticity in Filipino folk dance. Sociological Perspectives 43, 21-41.

Greenhalgh T and Wessely S (2004) 'Health for me': a sociocultural analysis of healthism in the middle classes. British Medical Bulletin 69, 197-213.

Grönlund E, Renck B and Weibull J (2005) Dance/movement therapy as an alternative treatment for young boys diagnosed as ADHD: a pilot study. American Journal of Dance Therapy 27, 63-85.

Guest G, MacQueen KM and Namey EE (2012) Applied Thematic Analysis. London: Sage.

Hammersley M and Atkinson P (1995) Ethnography. Principles in Practice. London: Routledge.

Hardin KL (1988) Aesthetics and the cultural whole: a study of Kono dance occasions. Empirical Studies of the Arts 6, 35-57.

Hurd Clarke L and Korotchenko A (2011) Aging and the body: a review. Canadian Journal on Aging 30, 495-510.

Katz S (2018) Introduction. In Katz S (ed.), Ageing in Everyday Life. Materialities and Embodiments. Bristol, UK: Policy Press, pp. 23-29.

Kaufman G and Elder Jr GH (2002) Revisiting age identity: a research note. Journal of Aging Studies 16, $169-176$. 
Keogh JWL, Kilding A, Pidgeon P, Ashley L and Gillis D (2009) Physical benefits of dancing for healthy older adults: a review. Journal of Ageing and Physical Activity 17, 479-500.

Klimczuk A (2016) Comparative analysis of national and regional models of the silver economy in the European Union. International Journal of Ageing and Later Life 10, 31-59.

Kraus R (2009) Straddling the sacred and secular: creating a spiritual experience through belly dance. Sociological Spectrum 29, 598-625.

Kraus R (2017) Gendered Bodies and Leisure. The Practice and Performance of American Belly Dance. London: Routledge.

Krekula C (2009) Age coding: on age-based practices of distinction. International Journal of Ageing and Later Life 4, 7-31.

Krekula C (2016) Contextualizing older women's body images: time dimensions, multiple reference groups and age codings of appearance. International Journal of Women and Ageing 28, 58-67.

Krekula C (2019) Time, precarisation and age normality: on job mobility among men in manual work. Ageing \& Society 39, 2290-2307.

Krekula C and Johansson B (2017) Introduktion [Introduction]. In Krekula C and Johansson B (eds), Kritiska Åldersstudier [Introduction to Critical Age Studies]. Malmö, Sweden: Studentlitteratur, pp. 11-38.

Krekula C, Arvidson M, Heikkinen S, Henriksson A and Olsson E (2017) On grey dancing: constructions of age-normality through choreography and temporal codes. Journal of Aging Studies 42, 38-45.

Krekula C, Nikander P and Wilińska M (2018) Multiple marginalisations based on age-gendered ageism and beyond. In Ayalon L and Tesch-Roemer C (eds), Contemporary Perspectives on Ageism. Cham, Switzerland: Springer Open, pp. 33-50.

Laroche J, Berardi A-M and Brangier E (2014) Embodiment of intersubjective time: relational dynamics as attractors in the temporal coordination of interpersonal behaviors and experiences. Frontiers in Psychology 5, 1180.

Lavigne GL, Forest J and Crevier-Braud L (2012) Passion at work and burnout: a two-study test of the mediating role of flow experiences. European Journal of Work and Organizational Psychology 21, 518-546.

Lawrie R (1980) Passion. Philosophy and Phenomenological Research 41, 106-126.

Leccardi C (2014) Time of society and time of experience: multiple times and social change. KronoScope 14, $10-24$.

Marion JS (2008) Ballroom. Culture and Costume in the Competitive Dance. Oxford: Berg Publisher.

Marshall BL (2018) Our Fitbits, our (ageing) selves: wearables, self-tracking and ageing embodiment. In Katz S (ed.), Ageing in Everyday Life. Materialities and Embodiments. Bristol, UK: Policy Press, pp. 197-215.

McGuire M (2007) Embodied practices: negotiation and resistance. In Ammerman NT (ed.), Everyday Religion. Observing Modern Religious Lives. Oxford: Oxford University Press, pp. 187-200.

Moe AM (2014) Sequins, sass, and sisterhood: an exploration of older women's belly dancing. Journal of Women \& Aging 26, 39-65.

Nadasen K (2008) 'Life without line dancing and the other activities would be too dreadful to imagine': an increase in social activity for older women. Journal of Women \& Aging 20, 329-342.

Paulson S (2009) An Exploration of How Various 'Cultures of Dance' Construct Experiences of Health and Growing Older. London: City University London.

Petersen A and Lupton D (1996) The New Public Health: Health and Self in the Age of Risk. London: Sage.

Radler D (1998) How a Dance Competition is Judged. Available at http://www.ballroomdance.net/ How_a_Competition_is_Judged_html.

Roberson Jr DN and Pelclova J (2014) Social dancing and older adults: playground for physical activity. Ageing International 39, 124-143.

Ronström O (1998) Pigga pensionärer och populärkultur? [Energetic Pensioners and Popular Culture?]. Stockholm: Carlssons bokförlag.

Rosa H (2013) Social Acceleration. A New Theory of Modernity. New York, NY: Columbia University Press.

Rowe JW and Kahn RL (1998) Successful Ageing. New York, NY: Random House.

Savigliano ME (1998) From wallflowers to femme fatales: tango and the performance of passionate feminity. In Washabaugh W (ed.), The Passion of Music and Dance: Body, Gender and Sexuality. Oxford: Berg, pp. 103-110. 
Starrin B and Steffner-Starrin L (2013) Sverige dansar [Sweden Dances]. Karlstad, Sweden: Starrin förlag. Stets J and Burke P (2000) Identity theory and social identity theory. Social Psychology Quarterly 63, 224237.

Stewart IJ (2000) Sacred Women, Sacred Dance: Awakening Spirituality Through Movement and Ritual. Rochester, VT: Inner Traditions.

Stryker S and Burke P (2000) The past, present, and future of an identity theory. Social Psychology Quarterly 63, 284-297.

Thomas H (1995) Dance, Modernity and Culture. Exploration in the Sociology of Dance. London: Routledge.

Thrift N (1997) The still point: resistance, embodiment and dance. In Pile S and Keith M (eds), Geographies of Resistance. London: Routledge, pp. 124-151.

Tulle E (2008) Ageing, the Body and Social Change: Running in Later Life. Basingstoke, UK: Palgrave Macmillan.

Ulvros EH (2004) Dansens och tidens virvlar. Om dans och lek i Sveriges historia [The Swirls of Dance and Time. On Dancing and Playing in Swedish History]. Lund, Sweden: Historiska Media.

Vallerand RJ and Verner-Filion J (2013) Making people's life most worth living: on the importance of passion for positive psychology. Terapia Psicologica 31, 35-48.

Varela FJ (1999) The specious present: a neurophenomenology of time consciousness. In Petitot J, Varela FJ, Pachoud BJ and Roy M (eds), Naturalizing Phenomenology: Issues in Contemporary Phenomenology and Cognitive Science. Stanford, CA: Stanford University Press, pp. 266-329.

Vatakis A, Sgouramani H, Gorea A, Hatzitak V and Pollick FE (2014) Time to act: new perspectives on embodiment and timing. Procedia - Social and Behavioral Sciences 126, 16-20.

Wallenstein S-O (2008) Introduktion. In Caprioli C and Wallenstein S-O (eds), Koreografier (Skriftserien Kairos No. 13). Stockholm: Raster Förlag, pp. 11-46 .

West-Pavlov R (2012) Temporalities. New York, NY: Routledge.

Westerhof GJ and Barrett AE (2005) Age identity and subjective well-being: a comparison of the United States and Germany. Journals of Gerontology: Psychological Sciences and Social Sciences 60B, 129-136.

Yin RK (2009) Case Study Research: Design and Methods. London: Sage.

Zerubavel E (1981) Hidden Rhythms: Schedules and Calendars in Social Life. Berkeley, CA: University of California Press.

Zerubavel E (1987) The language of time: toward a semiotics of temporality. Sociological Quarterly 28, 343-356.

Cite this article: Krekula C (2022). Pleasure and time in senior dance: bringing temporality into focus in the field of ageing. Ageing \& Society 42, 432-447. https://doi.org/10.1017/S0144686X20000926 